\title{
Arc protein expression after unilateral intracranial self-stimulation of the medial forebrain bundle is upregulated in specific nuclei of memory-related areas
}

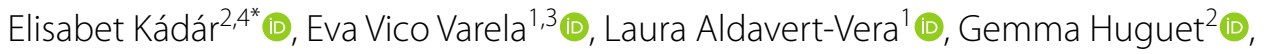
Ignacio Morgado-Bernal ${ }^{1}$ (iD and Pilar Segura-Torres ${ }^{1}$ (i)

\begin{abstract}
Background: Intracranial Self-Stimulation (ICSS) of the medial forebrain bundle (MFB) is a deep brain stimulation procedure, which has a powerful enhancement effect on explicit and implicit memory. However, the downstream synaptic plasticity events of MFB-ICSS in memory related areas have not been described thoroughly. This study complements previous work studying the effect of MFB-ICSS on the expression of the activity-regulated cytoskeletonassociated (Arc) protein, which has been widely established as a synaptic plasticity marker. We provide new integrated measurements from memory related regions and take possible regional hemispheric differences into consideration.

Results: Arc protein expression levels were analyzed $4.5 \mathrm{~h}$ after MFB-ICSS by immunohistochemistry in the hippocampus, habenula, and memory related amygdalar and thalamic nuclei, in both the ipsilateral and contralateral hemispheres to the stimulating electrode location. MFB-ICSS was performed using the same paradigm which has previously been shown to facilitate memory. Our findings illustrate that MFB-ICSS upregulates the expression of ArC protein in the oriens and radiatum layers of ipsilateral CA1 and contralateral CA3 hippocampal regions; the hilus bilaterally, the lateral amygdala and dorsolateral thalamic areas as well as the central medial thalamic nucleus. In contrast, the central amygdala, mediodorsal and paraventricular thalamic nuclei, and the habenular complex did not show changes in Arc expression after MFB-ICSS.
\end{abstract}

Conclusions: Our results expand our knowledge of which specific memory related areas MFB-ICSS activates and, motivates the definition of three functionally separate groups according to their Arc-related synaptic plasticity response: (1) the hippocampus and dorsolateral thalamic area, (2) the central medial thalamic area and (3) the lateral amygdala.

Keywords: Arc, Medial forebrain bundle, Intracranial self-stimulation, Memory, Hippocampus, Amygdala, Thalamus, Habenula

\footnotetext{
*Correspondence: elisabet.kadar@udg.edu

${ }^{4}$ Department of Biology, Sciences Faculty, University of Girona, C/Ma

Aurèlia Capmany 40, Camous Montilivi, 17003 Girona, Spain

Full list of author information is available at the end of the article
}

c The Author(s) 2018. This article is distributed under the terms of the Creative Commons Attribution 4.0 International License (http://creativecommons.org/licenses/by/4.0/), which permits unrestricted use, distribution, and reproduction in any medium, provided you give appropriate credit to the original author(s) and the source, provide a link to the Creative Commons license, and indicate if changes were made. The Creative Commons Public Domain Dedication waiver (http://creativecommons.org/ publicdomain/zero/1.0/) applies to the data made available in this article, unless otherwise stated. 


\section{Background}

Deep brain stimulation (DBS), an electrical current delivered through stereotactically implanted electrodes into specific areas of the brain, is a promising therapeutic option for patients with neurological and psychiatric diseases. To date, DBS has been successfully applied to alleviate movement disorders, such as Parkinson's disease [1]. DBS is now being considered for use as a treatment for neurodegenerative disorders associated with memory impairments such as Alzheimer's disease [2]. However, the mechanisms of action of how DBS affects memory are not yet fully known.

Studies with laboratory animals are required to explore potential targets and to analyze the underlying cellular and molecular brain changes of DBS. Recent studies indicate that bilateral DBS of the fornix/hypothalamic area drives neural activity in the cortico-hippocampal memory circuit with a significant reversal of the impaired cortical glucose utilization observed in patients with Alzheimer's disease [3, 4]. Further experiments in rats have established that forniceal DBS (F-DBS) induces increased hippocampal expression of c-Fos protein, some neurotrophic factors such as BDNF, and other synaptic plasticity markers [5], which are prominent molecular correlates of memory consolidation. These results are consistent with findings from our group which reveal a memory improvement after stimulating the medial forebrain bundle (MFB), the most important pathway of the brain reward system, which passes through the lateral hypothalamus (LH). Activation of brain areas belonging to the reward system generates positive reinforcement, and actions that are positively reinforced are more likely to be repeated than those that do not. Intracranial self-stimulation (ICSS) is a DBS procedure in which subjects self-administer electrical stimulation to brain reward areas by performing an instrumental response, such as pressing a lever in a Skinner box. The use of ICSS in animals allows us to unequivocally ensure that stimulation activates the reward system in a functional manner. In a similar way to F-DBS, ICSS of the LH has a reliable enhancing effect on hippocampus-dependent explicit memory [6-8]. However, while F-DBS affects fornix fibers, ICSS of the LH activates the MFB. Due to the extensive network of the MFB connects, this causes a widespread state of arousal and simultaneous activation of many areas, some of which are associated with different memory systems [9]. This could explain the wide therapeutic effects that MFB-ICSS appears to have in relation to different memory types. In addition to explicit memory, MFB-ICSS also improves performance in implicit memory tasks [10-12]. Most notable are the effects on emotional memory as measured by amygdala-dependent active avoidance tasks, in which ICSS reverses the memory deficit caused by aging [13, $14]$ and/or brain damage $[15,16]$.

Consistent with the broad effect of MFB-ICSS on different types of learning tasks, c-Fos expression results suggest ICSS activates multiple regions related to different memory systems, such as the amygdala, the dorsal striatum, the hippocampus and the prefrontal cortex [10, 17-19]. Additionally, MFB-ICSS induces differential time course mRNA expression of some synaptic plasticity-related genes including Arc in the amygdala and the hippocampus $[18,19]$. ICSS-treated rats showing a facilitated spatial memory have also long-lasting structural changes including extended dendritic arborization of pyramidal CA1 neurons [6]. Thus, based on the fact that Arc protein is a well-known marker of synaptic plasticity events associated with the memory consolidation process [20] and is also involved in long-term spine enlargement [21], we initially set out to determine the effect of MFB-ICSS has on Arc protein levels in the different sub-regions of the hippocampus and in the retrosplenial cortex. We observed that after $4.5 \mathrm{~h}$ of unilateral MFB-ICSS, Arc protein levels increased significantly in the CA1 and DG hippocampal subfields ipsilateral to the stimulated hemisphere [22] but at this time contralateral regions were not analyzed. We also observed that MFBICSS increased Arc expression in the granular retrosplenial cortex (RSC), a hippocampus-related region involved in long-lasting memory storage [23]. This study showed a possible lateralization of the ICSS effects on Arc protein levels since changes were only observed in the ipsilateral, but not the contralateral hemisphere.

The current study provides new integrated data of the synaptic plasticity effects of the memory enhancing MFB-ICSS treatment on additional regions related to different memory systems and analyzes hemisphere differences. Arc protein expression was examined by immunohistochemistry in both ipsilateral and contralateral hemispheres $4.5 \mathrm{~h}$ after MFB-ICSS in each subject. The studied areas include (1) the hippocampal subfields, involved in spatial memory encoding and consolidation; (2) amygdalar nuclei involved in implicit emotional memory, including the associative lateral amygdala (LA) and the central nucleus (Ce), responsible for the autonomic components of emotions [24]; (3) higher order thalamic nuclei, such as the central medial (CM) and paraventricular (PV) nuclei related to memory through its role in regulation of arousal or attentional levels [25], and the mediodorsal (MD) and dorsolateral (DL) nuclei, considered to be relays to the hippocampus, amygdala and/or associative cortices, as well as being involved in learning and executive functions [26, 27]; and finally (4) the medial and the lateral habenula ( $\mathrm{MHb}$ and $\mathrm{LHb}$ ), 
involved in reward, emotional behavior and cognitive functions [28], which could also be implicated in the circuit in which MFB-ICSS affects memory via the inactivation of structures that project to it $[29,30]$.

Our findings show that the memory systems engaged by MFB-ICSS include the hilus, the oriens and radiatum layers of CA1 and CA3 hippocampal areas, the LA, DL and $\mathrm{CM}$ thalamic nuclei, in accordance with the idea that separate neural systems could operate in parallel to support the effects of ICSS on memory. In addition, a differential hemispheric Arc dependent-synaptic plasticity response to the MFB-ICSS treatment was observed in some of the analyzed regions.

\section{Methods}

\section{Subjects}

Twenty-five male Wistar rats were used in total, with a mean age of 96.20 days $(\mathrm{SD}=2.10)$ at the beginning of the experiment and an average weight of $361 \mathrm{~g}(\mathrm{SD}=22.7)$ at the time of surgery. All were bred at our laboratory and fed ad libitum. Animals were individually housed, kept under controlled temperature $\left(20-22{ }^{\circ} \mathrm{C}\right)$, humidity $(40-$ $70 \%$ ) and subjected to a light/dark cycle of $12 / 12 \mathrm{~h}$.

\section{Intracranial self-stimulation Stereotactic surgery}

A combination of Ketamine (Imalgene, $150 \mathrm{mg} / \mathrm{Kg}$, Merial, Lyon, France) and Xylazine (Rompun $8 \mathrm{mg} / \mathrm{kh}$, Bayer, Barcelona, Spain) was used to induce deep anesthesia in the subjects. Using a digital stereotactic apparatus (Stoelting Co., 51900, IL, USA), all animals were implanted chronically and unilaterally (right hemisphere) with a $150 \mu \mathrm{m}$ diameter monopolar stainless steel electrode (PlasticsOne, Roanoke, Va, USA). The tip of the electrode was placed at the $\mathrm{LH}$, within the fibers of the medial forebrain bundle, with the incisor bar set at $-2.7 \mathrm{~mm}$ below the interaural line and according to coordinates [31]: $\mathrm{AP}=-2.56 \mathrm{~mm} ; \mathrm{ML}=1.8 \mathrm{~mm}$ and $\mathrm{DV}=-8.5 \mathrm{~mm}$, using the cranium surface as a dorsal reference. ICSS electrodes were anchored to the skull with jeweler's screws and dental cement.

\section{ICSS behavior establishment}

After a recovery period of 7 days, subjects were randomly distributed in 2 experimental groups, one that received the ICSS treatment (ICSS group) and their respective control without MFB-ICSS (Sham group). In order to establish self-stimulation behavior behavioral shaping was performed on animals from the MFB-ICSS group using a skinner conditioning box $(25 \times 20 \times 20 \mathrm{~cm})$ (Campden Instruments, Ltd.) with a lever situated on one of the lateral walls and a light switching on in a contingent manner to the stimulation train. The stimulation consisted of sinusoidal wave currents, of $0.3 \mathrm{~s}$ in duration and $50 \mathrm{~Hz}$ in frequency, with an intensity ranging from 50 and $250 \mu \mathrm{A}$. The procedure included the reinforcement of successive approximations to both the lever and to the required action (lever press) by the animal, while attempting to find the minimum current intensity that gave a stable response of 250 lever presses in $5 \mathrm{~min}$, and self-stimulation until 500 reinforcements were reached. Establishment of the optimal intensity (OI) for each animal was performed in the corresponding ICSS treatment session as described in Segura-Torres et al. 1988 [32].

\section{ICSS treatment}

Four days after the OI was found, MFB-ICSS treatment was administered. This was done in a single session of 2500 self-administered trains of stimulant current at each particular OI using the same Skinner box where ICSS behavior had been established. The parameters of the stimulation in terms of frequency, intensity and number of trains administered were the same as previous studies since it has been shown to effectively enhance memory, both implicit [33-35] and explicit [6,8].

Control subjects were placed in the same operant box for $45 \mathrm{~min}$ to match the average time it took the ICSS subjects to self-administer the treatment, but without receiving any stimulation (sham session). One of the experimental subjects had to be removed from further analysis at this point in time, due to incomplete treatment.

\section{Arc Immunolocalization \\ Tissue collection}

The animals (ICSS: $n=7$, Sham: $n=10$ ) were anesthetized with a lethal dose of pentobarbital $(150 \mathrm{mg} / \mathrm{kg}$ body weight, i.p.) and perfused transcardially with a solution of $0.1 \mathrm{M}$ phosphate buffer saline (PBS), $\mathrm{pH} 7.4$, followed by a solution of $4 \%$ paraformaldehyde in PBS $4,5 \mathrm{~h}$ after MFB-ICSS or sham session. This interval has been used previously $[22,23]$ and chosen as an intermediate point where Arc induction persists after LTP, contextual fear conditioning and reversal learning in a T-maze [20, 21, 36, 37]. Brains were post-fixed in $4 \%$ paraformaldehyde in PBS solution for $4 \mathrm{~h}$ and then placed in $15 \%$ sucrose in PBS for 3 days and $30 \%$ sucrose in PBS at $4{ }^{\circ} \mathrm{C}$ until they sank. Serial coronal sections of cryopreserved brain (20- $\mu$ m-thick) were obtained in a cryostat (Cryocut 1800, with $2020 \mathrm{JUNG}$ microtome) at $-20{ }^{\circ} \mathrm{C}$, at coordinates between -2.50 and -3.36 AP to Bregma. They were then mounted onto SuperFrost/Plus slides (MenzekGläser, Braunschweig, Germany) and stored at $-80{ }^{\circ} \mathrm{C}$ until immunohistochemistry staining. 


\section{Immunohistochemistry}

Frozen coronal sections were washed in $0.05 \%$ Tween 20 in PBS 0.1 M (Wash Buffer solution), treated in 1\% distilled $\mathrm{H}_{2} \mathrm{O}_{2}$ for 15 min and incubated in TNB $(0,1 \mathrm{M}$ Tris- $\mathrm{HCl} \mathrm{pH} \mathrm{7.5,} \mathrm{0,15} \mathrm{M} \mathrm{NaCl} \mathrm{and} \mathrm{0.5 \%} \mathrm{Blocking} \mathrm{Rea-}$ gent; Perkin Elmer Life Sciences, Inc.) as a blocking solution. Sections were incubated in mouse Anti-Arc antibody (sc-166461, Santa Cruz Biotechnology, Inc.; Santa Cruz, CA, USA; diluted 1:50) for $48 \mathrm{~h}$ at $4{ }^{\circ} \mathrm{C}$ in a humidified chamber. Later the sections were washed and incubated in Biotinylated anti-mouse IgG antibody (Vector Laboratories Inc.; Burlingame, CA, USA; diluted $1: 100) \mathrm{ON}$ at $4{ }^{\circ} \mathrm{C}$. Finally, samples were incubated in Streptavidin-peroxidase (Perkin-Elmer Life Sciences, Inc., diluted $1: 100)$ for $2.5 \mathrm{~h}$ at room temperature and washed and incubated in DAB (Fisher) for $10 \mathrm{~min}$. Lastly, sections were dehydrated, mounted and cover slipped. No staining was observed in control slides without the primary or secondary antibodies.

\section{Data analysis}

Microphotographs were taken with a BX41 Olympus microscope attached to an Olympus DP70 digital camera (Japan) from four regions 1) the hippocampus, including CA1, CA3 and DG; 2) the CeA and LA amygdaloid areas; 3 ) the PV, CM, DL and MD thalamic nuclei, and 4) the $\mathrm{MHb}$ and LHb. The analysis of the hippocampus was further divided by layers and measurements were taken in the oriens, pyramidal and radiatum layers of CA1; the oriens, pyramidal, lucidum and radiatum layers of CA3 and the granular and molecular layers of the medial blade (mbDG) and lateral blade (lbDG) of the DG and the hilus. The image analysis software Image-J 1.43 (http:// rsb.info.nih.gov/ij/) was used to assess greyscale intensity levels using circular regions of interest (ROIs). An average of Arc intensity levels from three histological sections between bregma -2.50 and -3.36 for all regions. For the $\mathrm{CM}$ and PV, ipsilateral and contralateral sides were not taken into account.

\section{Statistics}

The statistical computer package program PASW Statistics 17.0 (SPSS) was used to process the data. Analyses of Arc intensity levels $/ \mathrm{mm}^{2}$ were conducted with a mixed ANOVA independent for each brain region. This corresponds to one between-group factor, the TREATMENT (sham or ICSS) and one within-group factor, the HEMISPHERE (ipsilateral or contralateral to electrode placement). A second within-group factor was considered for the hippocampal regions, the LAYER (3 for CA1, 4 for CA3, 5 for DG; see 2.3.3). Student's $t$ test was applied to analyze the ICSS effects on Arc expression in the PV and $\mathrm{CM}$ nuclei. Additionally, in order to study the underlying structure of the regions where significant ICSS effects on Arc expression were observed principal components analysis (PCA) with oblimin method of rotation was conducted. The $\alpha$ level for all tests was set at.05.

\section{Results \\ ICSS treatment}

The mean values $( \pm \mathrm{SD})$ of the ICSS variables of the ICSS group were: OI $(77.14 \pm 42.31 \mu \mathrm{A})$, highest response rate $(73.92 \pm 13.30$ responses $/ \mathrm{min})$, treatment duration $(50.42 \pm 8.97 \mathrm{~min})$ and number of responses in the treatment session (3052.42 \pm 233.60 lever pressings). Correlation analyses showed no relationship between the ICSS variables and Arc levels in any of the brain areas evaluated.

\section{Arc protein expression in different memory system areas following ICSS}

We analyzed the influence of unilateral MFB-ICSS on different memory-related brain areas using Arc protein as a marker of early synaptic plasticity and examined both the ipsilateral and contralateral hemispheres. We compared the expression of Arc protein in both the MFB-ICSS and Sham groups in discrete regions of the hippocampus, amygdala, thalamus and the habenula $4.5 \mathrm{~h}$ after treatment.

\section{Hippocampus}

ANOVA analysis revealed a statistical significant increase of Arc protein expression in the ICSS group compared to the Sham group in the CA1 region dependent on both hemisphere and layer [TREAT$\left.M E N T \times L A Y E R \times H E M I S P H E R E: \mathrm{F}_{(2,30)}=3.68 ; p=.037\right]$ (see Fig. 1a, b). Further simple effects analysis showed significant effects in the ipsilateral hemisphere $(p=.05)$, however, this was dependent on layer [TREATMENT $\times$ LAYER: $\left.\quad \mathrm{F}_{(3,48)}=2.68 ; p=.007\right]$. Thus ICSS increased Arc expression in the ipsilateral stratum oriens $\left[\mathrm{F}_{(1,15)}=4.93 ; p=.042\right]$ and radiatum $\left[\mathrm{F}_{(1,15)}=5.75 ; p=.03\right]$ layers but not in the pyramidal layer $(p=.07)$. In contrast, no effects of the ICSS were observed in the contralateral side $(p=.755)$ in any layer (oriens, $p=.360$; radiatum, $p=.319$; pyramidal, $p=.998$ ).

The increase in Arc protein expression in the CA3 region of the MFB-ICSS group compared to Sham $\left[\mathrm{F}_{(1,15)}=5,65 ; p=.031\right]$ was independent of both hemisphere and layer $[\times$ HEMISPHERE: $p=.442 ; \times L A Y E R$ : $p=.669$ ] (Fig. 1a). However, since certain hemisphere differences were observed depending on the layer [HEMISPHERE $\times$ LAYER: $\left.\mathrm{F}_{(3,48)}=3.9 ; p=.034\right]$, simple effects for each hemisphere were studied. Analysis showed significant ICSS effects in the contralateral side $(p=.038)$, but not in the ipsilateral $(p=.095)$. Specifically, an Arc 


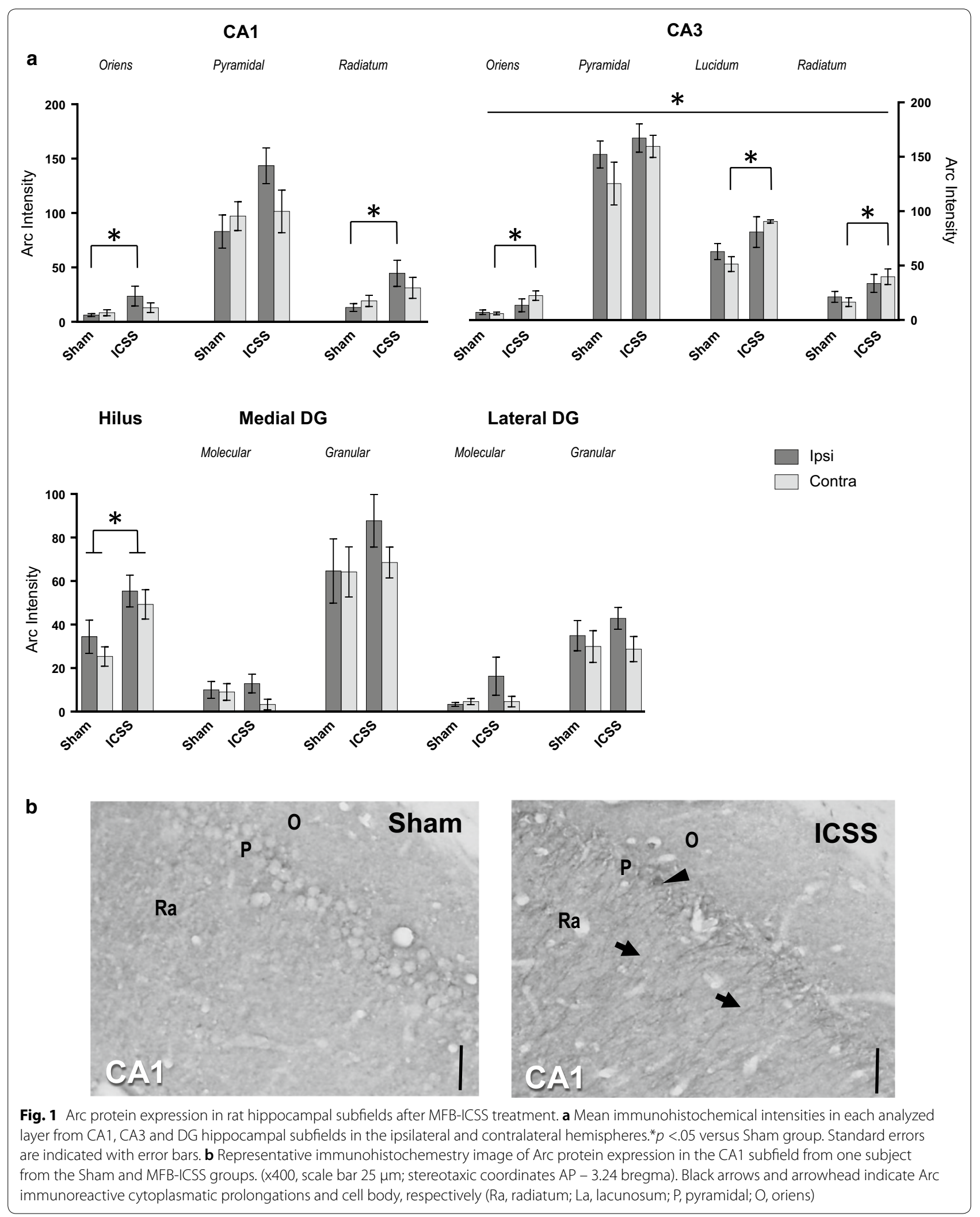


increase was observed in the contralateral stratum oriens $(p=0.004)$, lacunosum $(p=.05)$ and radiatum $(p=.016)$, but not in the pyramidal layer $(p=0.289)$.

Finally, MFB-ICSS treatment had no significant overall effect on the dentate gyrus $\left[\mathrm{F}_{(1,15)}=.663 ; p=.428\right]$ and no significant interactions ( $\times$ HEMISPHERE: $p=.275$; $\times$ LAYER: $p=.250$ ]. However, a significant difference in Arc protein increase between ICSS and Sham groups was observed in the Hilus $\left[\mathrm{F}_{(1,15)}=4.73 ; p=.046\right]$ independent of the hemisphere $(p=.683)$ and a tendency to significance in the ipsilateral molecular layer of lbDG $(p=.094)$, but not in the contralateral $(p=.885)$ was found (Fig. 1a).

\section{Amygdala}

Since the Box test for equality of covariance matrices was significant $(p=.010)$ in the LA, a conservative $\mathrm{F}$ correction was therefore applied. ANOVA revealed that the TREATMENT had a significant effect $\left[\mathrm{F}_{(1,7)}=6,51\right.$; $p=.038]$, independent of hemisphere $(p=.623)$. No significance was found in the CeA (TREATMENT: $p=.471$; TREATMENT $\times$ HEMISPHERE: $p=.407$ ) (see Fig. $2 \mathrm{~m}$ ).

\section{Thalamus}

Student's t-test showed a significant increase in Arc protein levels after MFB-ICSS treatment in the CM $\left[\mathrm{t}_{(9)}=4.59 ; p=.001\right]$ but not in the PV $\left[\mathrm{t}_{(13)}=0.910\right.$; $p=.379$ ] thalamic nuclei (see Fig. 2O). In the DL nucleus, the TREATMENT was found to have a significant effect [Box test $p=.027 ; \mathrm{F}_{(1,5)}=7.34 ; p=.042$ ] independent of hemisphere $(p=.076)$. In the MD, no significant effect of the TREATMENT factor [Box test $p=.04 ; \mathrm{F}_{(1,5)}=4.013$; $p=.101]$, nor the HEMISPHERE $(p=.467)$ or their interaction $(p=.279)$ were detected (see Fig. 2 n).

\section{Habenula}

ANOVA analysis revealed that the TREATMENT had no significant effects on either the medial $\left[\mathrm{F}_{(1,17)}=.331\right.$; $\boldsymbol{p}=.573]$ or lateral $\left[\mathrm{F}_{(1,17)}=1.815 ; \boldsymbol{p}=.196\right]$ habenula, or its interaction with the HEMISPHERE (MHb, $\boldsymbol{p}=.847$; LHb, $\boldsymbol{p}=.189$ ) (Fig. 3).

\section{Relations among Arc expression in different brain regions} Principal component analysis (PCA) was carried out on regions where significant effects of MFB-ICSS were observed, in order to identify whether or not there were any subsets of functionally-related regions to the expression of Arc. First of all, in order to reduce the variables of the analysis, we identified regions with significant correlation values between the ipsilateral and contralateral side (in relation to the electrode implantation) and in which the variable hemisphere did not influence the effects of the treatment. These areas were included in the PCA as the Arc intensity average of both hemispheres (LA, Hilus and DL variables) or in the region (CM). The CA1 and CA3 neurite layers also showed significant MFB-ICSS effects but with very different behavior in each of the hemispheres, however, this was not the case for the pyramidal layers. In this case, the CA1 and CA3 neurite layers were included in the PCA as Arc intensity average in oriens and radiatum layers from ipsilateral CA1 (CA1-neurite-ipsi) and in oriens, radiatum and lacunosum layers from contralateral CA3 (CA3-neuritecontra) variables. Therefore, the PCA included the following variables: LA, H, DL, CM, CA1-neurite-ipsi and CA3-neurite-contra.

Bartlett's sphericity test was statistically significant $(p=.005)$. A 3-component model explained 91.83 percent of the variance. Figure 4 shows rotated factor loading. Factor 1 included four items $(H$, neurite layers of contralateral CA3 and ipsilateral CA1 and the DL thalamus), and could be labeled "hippocampus + associative thalamus". Factor 2 consisted of the lateral amygdala and the unspecific CM thalamus mainly loaded onto the third factor. Factor correlations were low for factor $2(\mathrm{r} \leq .29)$ and moderated between factor 1 and $3(r=.59)$.

\section{Discussion}

This study analyzes Arc protein expression in specific memory-related brain regions including the hippocampus, amygdala, thalamus and habenula through which ICSS of the MFB could exert its enhancing effect on memory. Results showed that unilateral MFB-ICSS, delivered with the same parameters with which it facilitates memory, upregulated Arc protein expression in the CA1,

\footnotetext{
(See figure on next page.)

Fig. 2 Arc protein expression in amygdala nuclei ( $\mathbf{m})$ and thalamic nuclei (n and o) after MFB-ICSS treatment. Representative immunohistochemistry images of Arc protein expression in the lateral amydala (LA), dorsolateral (DL) and central medial (CM) thalamic nuclei from the Sham (a and $\mathbf{b}$, e and $\mathbf{f}, \mathbf{i}$ and $\mathbf{j}$ ) and MFB-ICSS (c and $\mathbf{d}, \mathbf{g}$ and $\mathbf{h}, \mathbf{k}$ and $\mathbf{I}$ ) groups. (scale bar $100 \mu \mathrm{m}$ in $\mathbf{a}, \mathbf{c}, \mathbf{e}, \mathbf{g}, \mathbf{i}$ and $\mathbf{k}$, and $25 \mu \mathrm{m}$ in $\mathbf{b}, \mathbf{d}, \mathbf{f}, \mathbf{h}, \mathbf{j}$, and $\mathbf{l}$; stereotaxic coordinates between - 2,50 and - 3.36 AP to Bregma). Arrows indicate Arc immunoreactive cell bodies. (CeA, central amygdala; ec, external capsule; DG, dentate girus; PV, paraventricular thalamic nuclei; IMD, intermediodorsal thalamic nucleus). Bar charts show the mean Arc expression levels in the LA and CeA (m) and in the DL and mediodorsal (MD) thalamic nuclei (n) from ipsi and contra lateral hemispheres of sham and MFB-ICSS treated groups. o mean Arc expression levels in CM and PV thalamic nuclei of sham and MFB-ICSS groups. Standard errors are indicated with error bars
} 

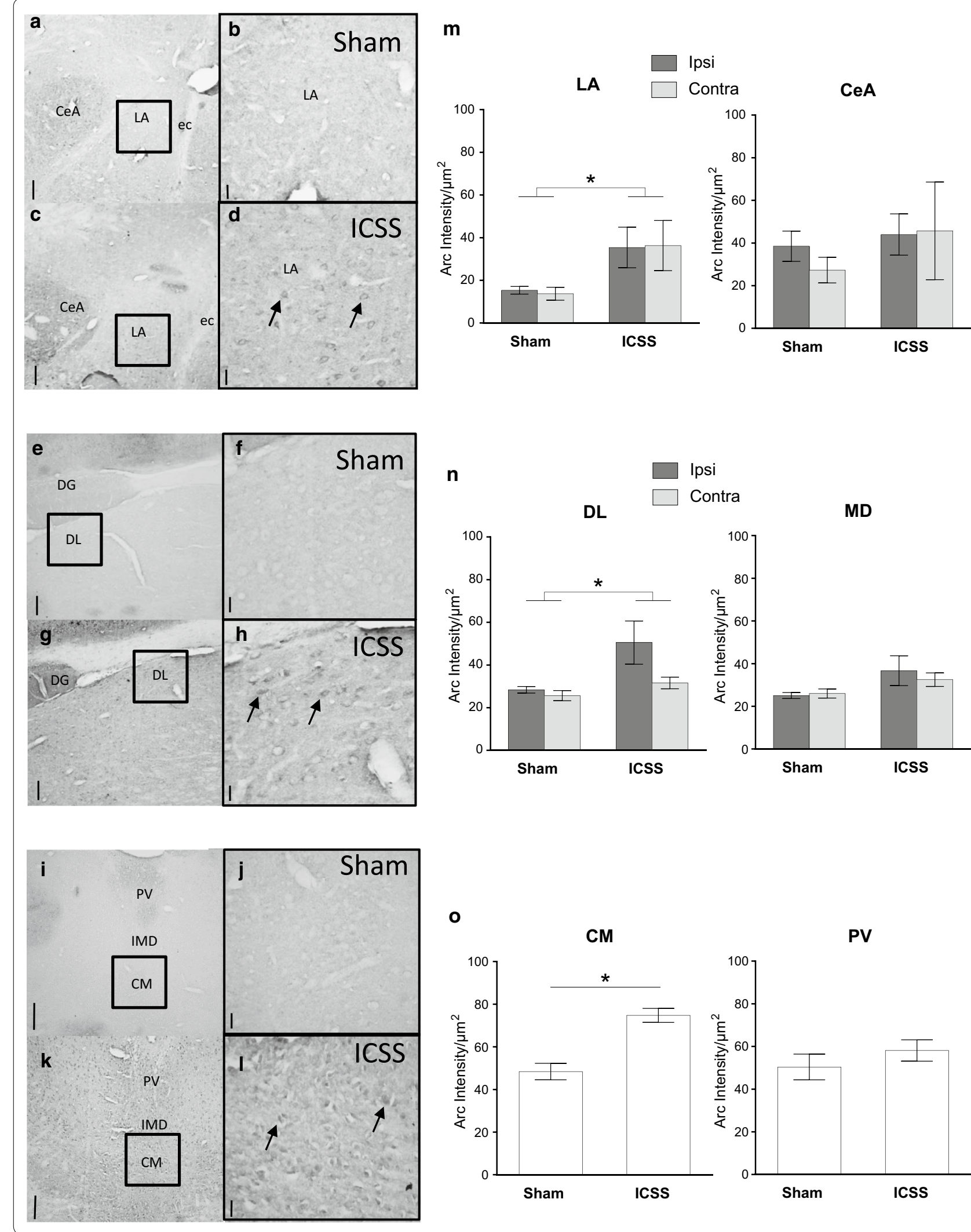

$\mathbf{0}$
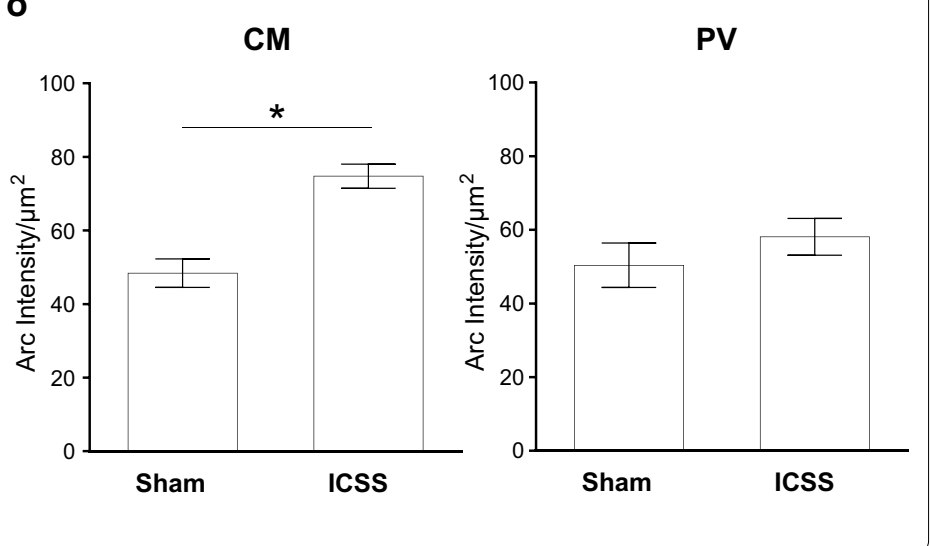


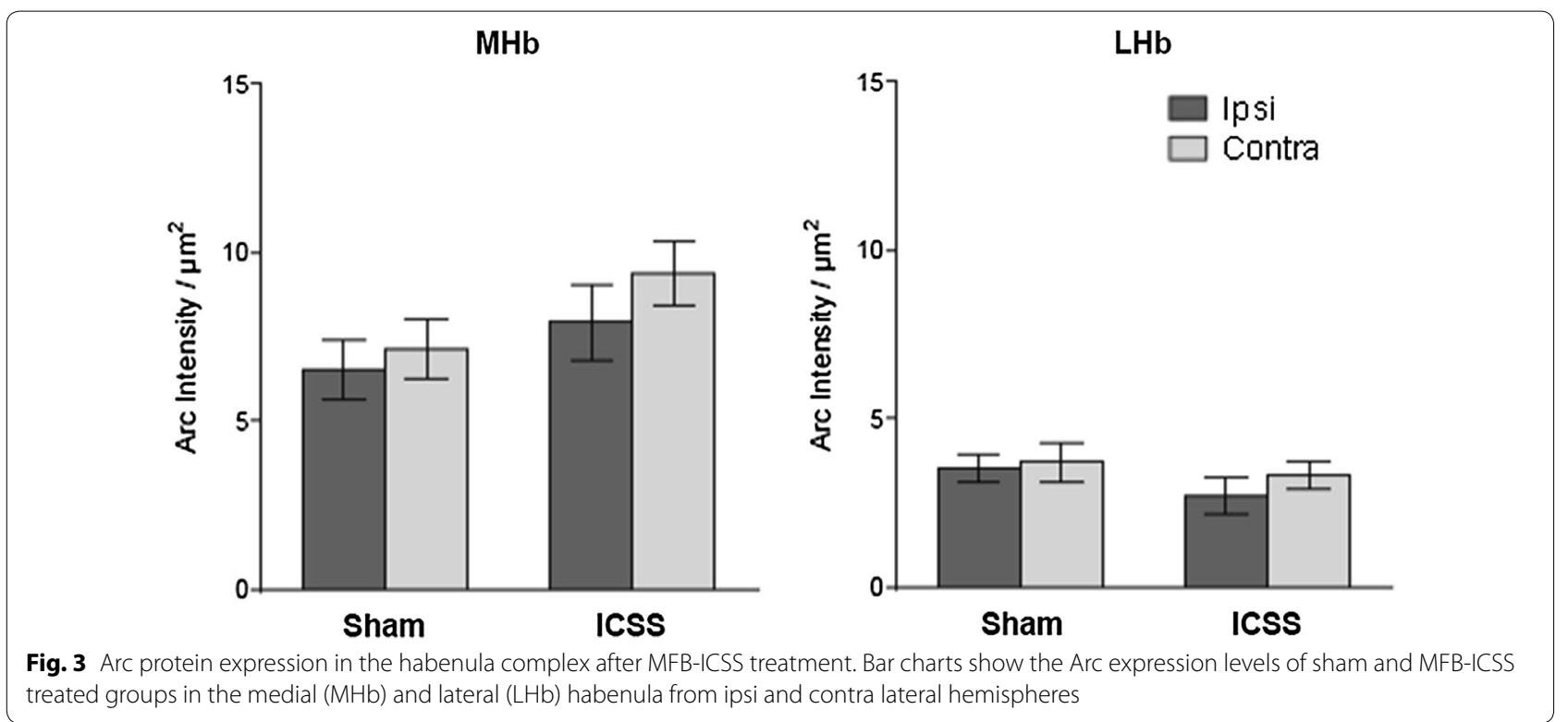

CA3 and hilus hippocampal regions, lateral amygdala, $\mathrm{CM}$ and DL thalamic nuclei. A differential hemispheric synaptic plasticity response was observed depending on the analyzed region.

Present results support our previous findings in that they show an overexpression of Arc protein in the neurite layers of the ipsilateral CA1 hippocampal region $4.5 \mathrm{~h}$ after MFB-ICSS [22], which is an intermediate time point for Arc protein expression changes [38]. This expression did not increase after the same treatment in contralateral CA1. To support our results further, structural plasticity changes, such as increased spine density and increased size and branching complexity in CA1 dendritic arborizations were also detected, specifically in the ipsilateral CA1 region of the hippocampus, 3 days and 20 days postMFB-ICSS [6]. In contrast, Arc expression in the CA3 subfield showed predominance in the contralateral hemisphere which indicates that the lack of MFB-ICSS effects previously reported on ipsilateral CA3 is a hemispheredependent effect. Previous results of c-Fos expression showing the bilateral activation of CA1 and CA3 after unilateral MFB-ICSS [10] suggest that the hemispheric differences are not a result of higher contralateral hemispheric activation but rather a higher plasticity response. Therefore, differential expression patterns between these two proteins may be a sign of the greater specificity of Arc protein expression in terms of plasticity. Interestingly, hemispheric asymmetry was found in CA3-CA1 pyramidal neuron synapses [39]. This asymmetry has also been observed in long-term memory, where only left CA3 silencing impaired performance in an associative spatial long-term memory task, whereas right CA3 silencing had no effect, suggesting that memory could be routed via distinct left-right pathways within the mouse hippocampus [40]. In the DG, although a global effect was not observed, a significant bilateral increase in Arc expression in the hilus was found, as well as a tendency towards significance in the ipsilateral molecular layer of the lbDG. This reflects sub-regional treatment-induced differences related to synaptic plasticity, similar to previous studies [22].

It has been shown that an analogous MFB-ICSS treatment induces expression changes of different synaptic plasticity-related genes such as Arc and BDNF in the rat amygdaloid complex [19]. However, Arc expression was not analyzed at the protein level in specific amygdala nuclei after MFB-ICSS. Boundaries of expression corresponding to cytoarchitectonically defined amygdala subnuclei have been described in basal conditions [41] and here we observed a significant increase in Arc protein expression $4.5 \mathrm{~h}$ after MFB-ICSS treatment in the LA nucleus, whereas no effects were observed in the CeA nucleus. Interestingly, Partin et al. [42] described notable differences in gene expression patterns in the CeA and the LA nuclei. This differential response after MFB-ICSS in LA supports additional experiments in our laboratory in which a differential acetylcholinesterase activity linked to synaptic plasticity events in the LA but not in CeA regions was observed in MFB-ICSS treated lesioned rats. At the behavioral level, MFB-ICSS completely reversed the impairment in the acquisition of an active avoidance task caused by amygdala lesions [15]. There are also functional differences between these two amygdalar regions. The LA is an essential region for fear memory storage 


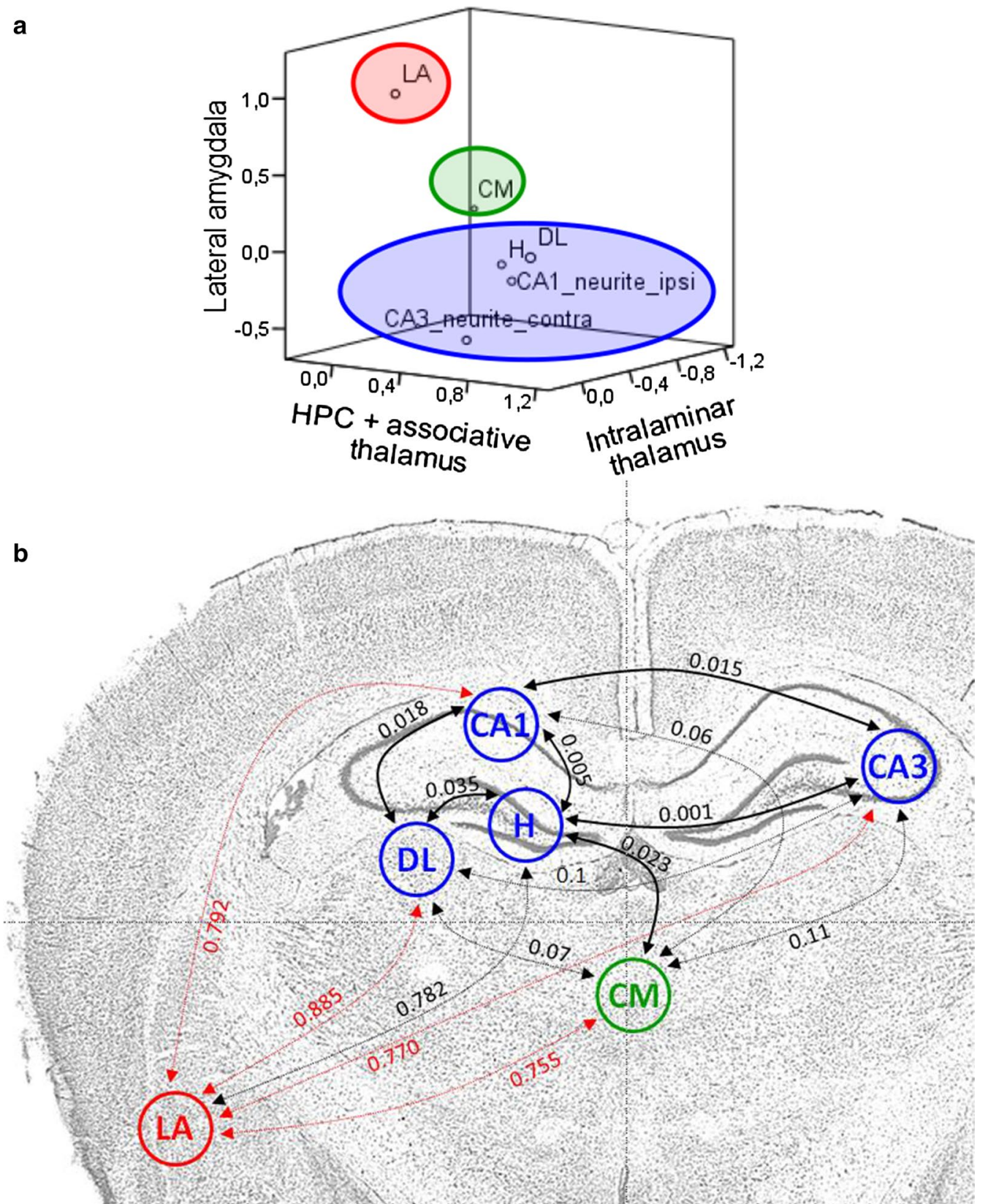

Fig. 4 Component graphic in rotated space showing brain regions with Arc-related plasticity as a consequence of the MFB-ICSS treatment. a Three-dimensional representation of the regions where the MFB-ICSS has significant effects, according to the correlation between the observed Arc protein levels. Three components were extracted, the first composed of different fields of the hippocampus and the dorsolateral associative nucleus of the thalamus (blue); the second by the lateral amygdala (red) and the third by the nonspecific thalamic nucleus CM (green) (Bartlett's sphericity test, $p=.005$ ). $\mathbf{b}$ Anatomical representation showing $p$ values of correlations between the different areas according to the observed Arc protein levels $4.5 \mathrm{~h}$ post-MFB-ICSS

whereas the CeA does not seem to be required for the manifestation of instrumental active avoidance conditioned responses [43]. In agreement with our results, the immediate-early gene Arc has been recognized as a molecular marker for the LA neuronal ensemble recruited during fear learning in mice [44]. Regarding the observed MFB-ICSS hemisphere effects, it is important to point out that while an ipsilateral and contralateral pattern of Arc expression was observed in CA1 and CA3 respectively, a bilateral increased Arc expression was 
obtained in the LA, in a way that is consistent with the previous cited works, since no hemispheric effects were reported.

Regarding the thalamus, the effects of MFB-ICSS on thalamic synaptic plasticity events related to learning and memory have not been described and few studies have explored this area after electrical stimulation. For instance, LTP and/or LTD have been observed in the anterior thalamus after stimulation of direct and indirect hippocampal projections [45] and Arc protein synthesis has only been explored in relation to the thalamus role as a sensory relay $[46,47]$. Present results show that MFB-ICSS induces bilateral Arc expression changes in specific thalamic nuclei including the DL and CM nuclei, whose role in memory may account for improvements in learning tasks. The DL nucleus acts in concert with the anterior nuclei and may serve an important integrative purpose for spatial learning systems [48-50]. The $\mathrm{CM}$ nucleus, strongly connected to the $\mathrm{mPFC}$, is likely to be involved in working memory and/or memory consolidation through its modulation of vigilance states [25, 51]. Contrary to expectations, under present conditions MFB-ICSS did not increase Arc protein expression in the DM and PV nuclei, even though they also seem to participate in memory and executive function. The MD nucleus may contribute more to adaptive decision-making, as it is connected to the orbital prefrontal cortex and basolateral amygdala [52]. The PV nucleus, being part of the dorsal midline group, seems to contribute to viscerolimbic functions, reward and defensive behavior, and is a relay station between specific parts of the prefrontal and cingulate cortex, the striatum, and the CeA [25, $53,54]$. Overall, these results indicate that the thalamic nuclei most directly related to memory may mediate the facilitation effects of the MFB- ICSS on memory to some extent. Furthermore, in the same way that MFB-ICSS has proven to potentiate both explicit and implicit memory, the thalamus has also been linked to both memory systems involved. Thus, recent enhancement of c-Fos activity and the alpha4-nicotinic acetylcholine receptor in the hippocampus was observed after central thalamic DBS treatment [55], and expression of genes related to protein synthesis, maturation and degradation are increased in thalamic neurons that project to the LA after fear conditioning [56].

Our results also suggest the existence of certain functional subsystems in regions showing Arc-related plasticity as a consequence of the MFB-ICSS treatment. On the one hand, it is worth noting the autocorrelation between the different parts of the hippocampus and also their functional connection with the DL [57, 58], but not with the CM nucleus of the thalamus. The notion that the latter involves a second subsystem or component is supported by the described lack of direct anatomical connections between the intralaminar thalamus and the hippocampus [25]. The associative LA is a substrate of action of the MFB-ICSS functionally independent of the hippocampus-DL and CM subsystems. However, since Arc and other plasticity and neuroprotection genes are upregulated in the amygdala before the 4,5 h time point (90 min post MFB-ICSS) [19], we cannot rule out that the activation of the amygdala and hippocampus, or thalamus, could be sequential, yet still related (Additional file 1 ).

The contribution of the habenular complex to ICSS has been examined in different studies but contradictory results have been observed. While Morissette et al. [59] showed that electrolytic lesions of the habenula attenuate brain stimulation reward, Gifuni et al. [60] showed that neurotoxic lesions of the LHb neurons do not alter the reward-enhancing effect of D-amphetamine in ICSS. Duchesne et al. [61] concluded that mesohabenular dopamine is not an important contributor to brain stimulation reward. Moreover, though recent evidence indicates that the habenular complex plays a role in learning and memory [62], no studies have looked at the effects of ICSS on plasticity-related protein expression in the habenula. Our findings show that MFB-ICSS did not enhance habenular Arc protein expression levels (or c-Fos protein expression- data not shown), at least at the time point analyzed. This supports the idea that the habenular complex may not be involved in the anatomical circuit activated by ICSS.

Finally, all these results taken together support the hypothesis that the stimulation of the reward system activates neural plasticity mechanisms in memory related areas and point MFB as a promising target for memory enhancing treatments. However, an aspect to consider is whether the results obtained with MFBICSS could be expected when MFB-stimulation was not self-administered, as it would be in a clinical setting. Although there are no antecedents comparing Arc protein levels caused by passive versus active administration, studies have reported that this variable slightly affects the induction c-Fos expression in the ipsilateral LH, but does not affect other brain memory-related regions [63]. Moreover, Chergui et al. [64] considered that, more than being self-administered or not, a critical parameter of the stimulation could be the temporal organization of the action potentials they generate. Similarly, although at the behavioral level both procedures-self-administered and experimenter-administered- have been shown to facilitate memory [65], the reinforcement component would correlate with the efficiency to potentiate memory [66]. Further studies should be performed to elucidate the differences 
between these two stimulation paradigms more thoroughly.

\section{Conclusions}

Overall, MFB-ICSS upregulates the expression of Arc protein in specific memory related areas including the CA1, CA3 and hilus hippocampal regions, the lateral amygdala and the dorsolateral and central medial thalamic nuclei which showed differential hemispheric response to the treatment. Our findings back up the idea that multiple, separate brain systems, could operate in parallel to support MFB-ICSS behavioral effects with distinct purposes during memory consolidation. Further studies may be performed not only to rule out the contribution from any other long-term storage related areas, such as the medial prefrontal cortex, but also to analyze whether ICSS may reverse the impact that certain brain lesions may have on cognition and memory, by potentiating other functionally related areas.

\section{Additional file}

Additional file 1. In the Additional file 1, titled DATA BASE_Arc, it is included all raw data of Arc intensity levels in all subregions from amygdala, thalamus, hippocampus and habenula regions in ipsilateral (i) and contralateral (c) hemispheres in the sham group (0) and ICSS group (1) according to the described methodology (each data is the average of Arc intensity levels from three histological sections from each rat).

\section{Abbreviations}

Arc: activity-regulated cytoskeleton-associated; CM: central medial; Ce: central nucleus; DBS: deep brain stimulation; DL: dorsolateral; ICSS: Intracranial SelfStimulation; F-DBS: forniceal DBS; LA: lateral amygdala; IbDG: lateral blade of DG; LHb: lateral habenula; LH: lateral hypothalamus; mbDG: medial blade of the DG; MFB: medial forebrain bundle; MHb: medial habenula; MD: mediodorsal; Ol: optimal intensity; PV: paraventricular; PBS: phosphate buffer saline; PCA: principal components analysis; ROls: regions of interest; RSC: retrosplenial cortex.

\section{Authors' contributions}

EV performed Arc immunohistochemistry of all brain sections and contributed in MFB-ICSS procedures with LA and PS. EK, PS, GH and IM analyzed and interpreted data regarding Arc immunolocalization. EK and PS were the major contributors in writing the manuscript and GH, LA, EV and IM revising it critically. All authors agreed to be accountable in ensuring appropriate answer to questions related to the accuracy and integrity of any part of the work. All authors read and approved the final manuscript.

\section{Author details}

${ }^{1}$ Departament de Psicobiologia i de Metodologia de les Ciències de la Salut, Institut de Neurociències, Universitat Autónoma de Barcelona, 08193 Bellaterra, Barcelona, Spain. ${ }^{2}$ Departament de Biologia, Universitat de Girona, 17071 Girona, Spain. ${ }^{3}$ Douglas Mental Health University Institute, McGill University, Montreal, QC H4H 1R3, Canada. ${ }^{4}$ Department of Biology, Sciences Faculty, University of Girona, C/Ma Aurèlia Capmany 40, Camous Montilivi, 17003 Girona, Spain.

\section{Acknowledgements}

We wish to thank Soleil Garcia-Brito, Daniel Rico and Neus Biosca for their excellent technical help, and Dr. Eva Penelo for her selfless aid with the analysis of the principal components.

\section{Competing interests}

The authors declare that they have no competing interests.

\section{Availability of data and materials}

All data generated and analysed during this study are included in this published article (and its Additional files)

\section{Consent to publish}

Not applicable.

\section{Ethics approval and consent to participate}

This investigation does not involve human subject. All procedures were carried out in compliance with the European Community Council Directive for care and use of laboratory animals (2010/63/EU) and the protocol was approved by the Ethics Committee at the Universitat Autònoma de Barcelona, with order number 4465. All efforts were made to minimize the number of animals used.

\section{Funding}

This research was supported by a grant support from the Spanish Ministerio de Ciencia e Innovación (I+D projects PSI2013-41018-P; PSI2017-83202-C21-P and (2-2-P)

\section{Publisher's Note}

Springer Nature remains neutral with regard to jurisdictional claims in published maps and institutional affiliations.

Received: 21 October 2017 Accepted: 31 July 2018

Published online: 08 August 2018

\section{References}

1. Ponce FA, Lozano AM. Deep brain stimulation state of the art and novel stimulation targets. Prog Brain Res. 2010;184:311-24.

2. Suthana N, Fried I. Deep brain stimulation for enhancement of learning and memory. Neuroimage. 2014;85(Pt 3):996-1002. https://doi. org/10.1016/j.neuroimage.2013.07.066.

3. Sankar T, Chakravarty MM, Bescos A, Lara M, Obuchi T, Laxton AW, et al. Deep brain stimulation influences brain structure in Alzheimer's disease. Brain Stimul. 2014. https://doi.org/10.1016/j.brs.2014.11.020.

4. Smith GS, Laxton AW, Tang-Wai DF, McAndrews MP, Diaconescu AO, Workman Cl, et al. Increased cerebral metabolism after 1 year of deep brain stimulation in Alzheimer disease. Arch Neurol. 2012;69:1141-8. https://doi.org/10.1001/archneurol.2012.590.

5. Gondard E, Chau HN, Mann A, Tierney TS, Hamani C, Kalia SK, et al. Rapid modulation of protein expression in the rat hippocampus following deep brain stimulation of the fornix. Brain Stimul. 2015. https://doi. org/10.1016/j.brs.2015.07.044.

6. Chamorro-López J, Miguéns M, Morgado-Bernal I, Kastanauskaite A, Selvas A, Cabané-Cucurella A, et al. Structural plasticity in hippocampal cells related to the facilitative effect of intracranial self-stimulation on a spatial memory task. Behav Neurosci. 2015. https://doi.org/10.1037/bne0000098

7. Ruiz-Medina J, Morgado-Bernal I, Redolar-Ripoll D, Aldavert-Vera L, Segura-Torres P. Intracranial self-stimulation facilitates a spatial learning and memory task in the Morris water maze. Neuroscience. 2008;154:424-30.

8. Soriano-Mas C, Redolar-Ripoll D, Aldavert-Vera L, Morgado-Bernal I, Segura-Torres P. Post-training intracranial self-stimulation facilitates a hippocampus-dependent task. Behav Brain Res. 2005;160:141-7.

9. Berthoud $H-R$, Münzberg $H$. The lateral hypothalamus as integrator of metabolic and environmental needs: from electrical self-stimulation to opto-genetics. Physiol Behav. 2011;104:29-39. https://doi.org/10.1016/j. physbeh.2011.04.051.

10. Aldavert-Vera L, Huguet G, Costa-Miserachs D, de Ortiz SP, Kádár E, Morgado-Bernal I, et al. Intracranial self-stimulation facilitates activeavoidance retention and induces expression of c-Fos and Nurr1 in rat brain memory systems. Behav Brain Res. 2013;250:46-57. https://doi. org/10.1016/j.bbr.2013.04.025. 
11. Coulombe D, White N. The effect of post-training hypothalamic self-stimulation on sensory preconditioning in rats. Can J Psychol. 1982;36:57-66.

12. García-Brito S, Morgado-Bernal I, Biosca-Simon N, Segura-Torres P. Intracranial self-stimulation also facilitates learning in a visual discrimination task in the Morris water maze in rats. Behav Brain Res. 2017:317:360-6. https://doi.org/10.1016/j.bbr.2016.09.069.

13. Aldavert-Vera L, Costa-Miserachs D, Massanes-Rotger E, Soriano-Mas C, Segura-Torres P, Morgado-Bernal I. Facilitation of a distributed shuttle-box conditioning with posttraining intracranial self-stimulation in old rats. Neurobiol Learn Mem. 1997;67:254-8.

14. Redolar-Ripoll D, Soriano-Mas C, Guillazo-Blanch G, Aldavert-Vera L, Segura-Torres P, Morgado-Bernal I. Posttraining intracranial self-stimulation ameliorates the detrimental effects of parafascicular thalamic lesions on active avoidance in young and aged rats. Behav Neurosci. 2003; 117:246-56

15. Kadar E, Ramoneda M, Aldavert-Vera L, Huguet G, Morgado-Bernal I, Segura-Torres P. Rewarding brain stimulation reverses the disruptive effect of amygdala damage on emotional learning. Behav Brain Res. 2014;274:43-52. https://doi.org/10.1016/j.bbr.2014.07.050.

16. Segura-Torres $P$, Aldavert-Vera L, Gatell-Segura A, Redolar-Ripoll D, Morgado-Bernal I. Intracranial self-stimulation recovers learning and memory capacity in basolateral amygdala-damaged rats. Neurobiol Learn Mem. 2010;93:117-26.

17. Arvanitogiannis A, Tzschentke TM, Riscaldino L, Wise RA, Shizgal P. Fos expression following self-stimulation of the medial prefrontal cortex. Behav Brain Res. 2000;107:123.

18. Huguet G, Aldavert-Vera L, Kádár E, Pena de Ortiz S, Morgado-Bernal I, Segura-Torres P. Intracranial self-stimulation to the lateral hypothalamus, a memory improving treatment, results in hippocampal changes in gene expression. Neuroscience. 2009;162:359-74.

19. Kadar E, Aldavert-Vera L, Huguet G, Costa-Miserachs D, Morgado-Bernal I, Segura-Torres P. Intracranial self-stimulation induces expression of learning and memory-related genes in rat amygdala. Genes Brain Behav. 2011;10:69-77.

20. Korb E, Finkbeiner S. Arc in synaptic plasticity: from gene to behavior Trends Neurosci. 2011;34:591-8. http://www.pubmedcentral.nih.gov/ articlerender.fcgi?artid=3207967\&tool=pmcentrez\&rendertype=abstr act. Accessed 15 Mar 2016.

21. Messaoudi E, Kanhema T, Soule J, Tiron A, Dagyte G, da Silva B, et al. Sus tained Arc/Arg3.1 synthesis controls long-term potentiation consolidation through regulation of local actin polymerization in the dentate gyrus in vivo. J Neurosci. 2007:27:10445-55.

22. Kadar E, Huguet G, Aldavert-Vera L, Morgado-Bernal I, Segura-Torres P. Intracranial self stimulation upregulates the expression of synaptic plasticity related genes and Arc protein expression in rat hippocampus. Genes Brain Behav. 2013;12:771-9.

23. Kádár E, Vico-Varela E, Aldavert-Vera L, Huguet G, Morgado-Bernal I, Segura-Torres P. Increase in c-Fos and Arc protein in retrosplenial cortex after memory-improving lateral hypothalamic electrical stimulation treatment. Neurobiol Learn Mem. 2016;128:117-24

24. Izquierdo I, Furini CRG, Myskiw JC. Fear memory. Physiol Rev. 2016;96:695-750. https://doi.org/10.1152/physrev.00018.2015.

25. de Vasconcelos Pereira. A, Cassel J-C. The nonspecific thalamus: a place in a wedding bed for making memories last? Neurosci Biobehav Rev. 2015;54:175-96. https://doi.org/10.1016/j.neubiorev.2014.10.021.

26. Clark BJ, Harvey RE. Do the anterior and lateral thalamic nuclei make distinct contributions to spatial representation and memory? Neurobiol Learn Mem. 2016;133:69-78. https://doi.org/10.1016/j.nlm.2016.06.002.

27. Mitchell AS. The mediodorsal thalamus as a higher order thalamic relay nucleus important for learning and decision-making. Neurosci Biobehav Rev. 2015;54:76-88. https://doi.org/10.1016/j.neubiorev.2015.03.001.

28. Lecourtier L, Deschaux O, Arnaud C, Chessel A, Kelly PH, Garcia R. Habenula lesions alter synaptic plasticity within the fimbria-accumbens pathway in the rat. Neuroscience. 2006;141:1025-32. https://doi. org/10.1016/j.neuroscience.2006.04.018.

29. Lecourtier L, DeFrancesco A, Moghaddam B. Differential tonic influence of lateral habenula on prefrontal cortex and nucleus accumbens dopamine release. Eur J Neurosci. 2008;27:1755-62. https://doi.org/10.11 11/j.1460-9568.2008.06130.x

30. Nishikawa T, Fage D, Scatton B. Evidence for, and nature of, the tonic inhibitory influence of habenulointerpeduncular pathways upon cerebral dopaminergic transmission in the rat. Brain Res. 1986;373:32436. http://www.ncbi.nlm.nih.gov/pubmed/2424555. Accessed 15 Mar 2017

31. Paxinos, G Watson C. The rat brain in stereotaxic coordinates. Sixth edit. Elsevier Academic Press; 2007.

32. Segura-Torres P, Capdevila-Ortis L, Marti-Nicolovius M, Morgado-Bernal I. Improvement of shuttle-box learning with pre- and post-trial intracranial self-stimulation in rats. Behav Brain Res. 1988;29:111-7.

33. Aldavert-Vera L, Segura-Torres P, Costa-Miserachs D, Morgado-Bernal I. Shuttle-box memory facilitation by posttraining intracranial self-stimulation: differential effects in rats with high and low basic conditioning levels. Behav Neurosci. 1996;110:346-52.

34. Aldavert-Vera L, Huguet G, Costa-Miserachs D, Ortiz SPD, Kádár E, Morgado-Bernal I, et al. Intracranial self-stimulation facilitates activeavoidance retention and induces expression of c-Fos and Nurr 1 in rat brain memory systems. Behav Brain Res. 2013;250:46-57.

35. Ruiz-Medina J, Redolar-Ripoll D, Morgado-Bernal I, Aldavert-Vera L, Segura-Torres P. Intracranial self-stimulation improves memory consolidation in rats with little training. Neurobiol Learn Mem. 2008;89:574-81.

36. Lee I, Kesner RP. Differential contributions of dorsal hippocampal subregions to memory acquisition and retrieval in contextual fearconditioning. Hippocampus. 2004;14:301-10. https://doi.org/10.1002/ hipo.10177.

37. Holloway CM, Mclntyre CK. Post-training disruption of Arc protein expression in the anterior cingulate cortex impairs long-term memory for inhibitory avoidance training. Neurobiol Learn Mem. 2011;95:425-32. https://doi.org/10.1016/j.n/m.2011.02.002.

38. Korb E, Wilkinson CL, Delgado RN, Lovero KL, Finkbeiner S. Arc in the nucleus regulates PML-dependent GluA1 transcription and homeostatic plasticity. Nat Neurosci. 2013;16:874-83. https://doi.org/10.1038/nn.3429.

39. Shinohara $Y$, Hirase $H$, Watanabe M, Itakura M, Takahashi M, Shigemoto R. Left-right asymmetry of the hippocampal synapses with differential subunit allocation of glutamate receptors. Proc Natl Acad Sci USA. 2008;105:19498-503. https://doi.org/10.1073/pnas.0807461105.

40. Shipton OA, El-Gaby M, Apergis-Schoute J, Deisseroth K, Bannerman DM, Paulsen O, et al. Left-right dissociation of hippocampal memory processes in mice. Proc Natl Acad Sci U S A. 2014;111:15238-43. https:// doi.org/10.1073/pnas.1405648111.

41. Zirlinger M, Kreiman G, Anderson DJ. Amygdala-enriched genes identified by microarray technology are restricted to specific amygdaloid subnuclei. Proc Natl Acad Sci USA. 2001;98:5270.

42. Partin AC, Hosek MP, Luong JA, Lella SK, Sharma SAR, Ploski JE. Amygdala nuclei critical for emotional learning exhibit unique gene expression patterns. Neurobiol Learn Mem. 2013;104:110-21. https://doi.org/10.1016/j. nlm.2013.06.015

43. Choi J-S, Cain CK, LeDoux JE. The role of amygdala nuclei in the expression of auditory signaled two-way active avoidance in rats. Learn Mem. 2010;17:139-47. http://www.pubmedcentral.nih.gov/articlerender. fcgi?artid=2832923\&tool=pmcentrez\&rendertype=abstract. Accessed 16 Mar 2016

44. Gouty-Colomer LA, Hosseini B, Marcelo IM, Schreiber J, Slump DE, Yamaguchi $S$, et al. Arc expression identifies the lateral amygdala fear memory trace. Mol Psychiatry. 2016;21:364-75. http://www.ncbi.nlm.nih.gov/ pubmed/25802982. Accessed 13 Mar 2017.

45. Tsanov M, Vann SD, Erichsen JT, Wright N, Aggleton JP, O'Mara SM. Differential regulation of synaptic plasticity of the hippocampal and the hypothalamic inputs to the anterior thalamus. Hippocampus. 2011;21:18. http://www.pubmedcentral.nih.gov/articlerender.fcgi?artid=39289 17\&tool=pmcentrez\&rendertype=abstract. Accessed 16 Mar 2016.

46. Khodadad A, Adelson PD, Lifshitz J, Thomas TC. The time course of activity-regulated cytoskeletal (ARC) gene and protein expression in the whisker-barrel circuit using two paradigms of whisker stimulation. Behav Brain Res. 2015;284:249-56. https://doi.org/10.1016/j.bbr.2015.01.032.

47. Ota KT, Monsey MS, Wu MS, Young GJ, Schafe GE. Synaptic plasticity and NO-cGMP-PKG signaling coordinately regulate ERK-driven gene expression in the lateral amygdala and in the auditory thalamus following Pavlovian fear conditioning. Learn Mem. 2010;17:221-35. https://doi. org/10.1101//m.1592510.

48. Aggleton JP, Nelson AJD. Why do lesions in the rodent anterior thalamic nuclei cause such severe spatial deficits? Neurosci Biobehav Rev. 2015;54:131-44. https://doi.org/10.1016/j.neubiorev.2014.08.013. 
49. Mizumori SJ, Williams JD. Directionally selective mnemonic properties of neurons in the lateral dorsal nucleus of the thalamus of rats. J Neurosci. 1993;13:4015-28. http://www.ncbi.nlm.nih.gov/pubmed/8366357.

50. van Groen T, Kadish I, Wyss JM. The role of the laterodorsal nucleus of the thalamus in spatial learning and memory in the rat. Behav Brain Res. 2002;136:329-37. https://doi.org/10.1016/S0166-4328(02)00199-7.

51. Mair RG, Hembrook JR. Memory Enhancement with Event-Related Stimulation of the Rostral Intralaminar Thalamic Nuclei. J Neurosci. 2008:28:14293-300. https://doi.org/10.1523/JNEUROSCI.3301-08.2008.

52. Mitchell AS, Sherman SM, Sommer MA, Mair RG, Vertes RP, Chudasama Y Advances in understanding mechanisms of thalamic relays in cognition and behavior. J Neurosci. 2014;34:15340-6. https://doi.org/10.1523/ JNEUROSCI.3289-14.2014.

53. Kirouac GJ. Placing the paraventricular nucleus of the thalamus within the brain circuits that control behavior. Neurosci Biobehav Rev. 2015;56:315-29. https://doi.org/10.1016/j.neubiorev.2015.08.005.

54. Penzo MA, Robert V, Tucciarone J, De Bundel D, Wang M, Van Aelst L, et al. The paraventricular thalamus controls a central amygdala fear circuit Nature. 2015;519:455-9. https://doi.org/10.1038/nature13978.

55. Lin H-C, Pan H-C, Lin S-H, Lo Y-C, Shen ET-H, Liao L-D, et al. Central thalamic deep-brain stimulation alters striatal-thalamic connectivity in cognitive neural behavior. Front Neural Circuits. 2015;9:87. http://www. pubmedcentral.nih.gov/articlerender.fcgi?artid $=4710746 \&$ tool=pmcen trez\&rendertype=abstract. Accessed 16 Mar 2016.

56. Katz IK, Lamprecht R. Fear conditioning leads to alteration in specific genes expression in cortical and thalamic neurons that project to the lateral amygdala. J Neurochem. 2015;132:313-26. https://doi.org/10.1111/ jnc.12983.

57. Aggleton JP. Understanding retrosplenial amnesia: insights from animal studies. Neuropsychologia. 2010;48:2328-38. https://doi.org/10.1016/j. neuropsychologia.2009.09.030.
58. Van der Werf Yd, Witter MP, Uylings HB, Jolles J. Neuropsycology of infarctions in the thalamus: a review. Neuropsychologia. 2000;38:613-27.

59. Morissette MC, Boye SM. Electrolytic lesions of the habenula attenuate brain stimulation reward. Behav Brain Res. 2008;187:17-26.

60. Gifuni AJ, Jozaghi S, Gauthier-Lamer AC, Boye SM. Lesions of the lateral habenula dissociate the reward-enhancing and locomotor-stimulant effects of amphetamine. Neuropharmacology. 2012;63:945-57. https:// doi.org/10.1016/j.neuropharm.2012.07.032.

61. Duchesne V, Boye SM. Differential contribution of mesoaccumbens and mesohabenular dopamine to intracranial self-stimulation. Neuropharmacology. 2013;70:43-50. https://doi.org/10.1016/j.neuropharm .2013.01.005.

62. Goutagny R, Loureiro M, Jackson J, Chaumont J, Williams S, Isope P, et al. Interactions between the lateral habenula and the hippocampus: implication for spatial memory processes. Neuropsychopharmacology. 2013;38:1-9. https://doi.org/10.1038/npp.2013.142.

63. Hunt GE, McGregor IS. Rewarding brain stimulation induces only sparse Fos-like immunoreactivity in dopaminergic neurons. Neuroscience. 1998;83:501-15.

64. Chergui K, Nomikos GG, Mathe JM, Gonon F, Svensson TH. Burst stimulation of the medial forebrain bundle selectively increase Fos-like immunoreactivity in the limbic forebrain of the rat. Neuroscience. 1996;72:141-56.

65. White N, Major R. Facilitation of retention by self-stimulation and by experimenter-administered stimulation. Can J Psychol. 1978;32:116-23.

66. Segura-Torres P, Portell-Cortes I, Morgado-Bernal I. Improvement of shuttle-box avoidance with post-training intracranial self-stimulation, in rats: a parametric study. Behav Brain Res. 1991:42:161-7.
Ready to submit your research? Choose BMC and benefit from:

- fast, convenient online submission

- thorough peer review by experienced researchers in your field

- rapid publication on acceptance

- support for research data, including large and complex data types

- gold Open Access which fosters wider collaboration and increased citations

- maximum visibility for your research: over 100M website views per year

At BMC, research is always in progress.

Learn more biomedcentral.com/submissions 